\title{
MEMÓRIA DO JUDÔ NA CIDADE DO RECIFE: UMA ANÁLISE A PARTIR DE SUA RELAÇÃO COM A EDUCAÇÃO E O PROCESSO CIVILIZATÓRIO
}

\author{
JUDO MEMORY IN THE CITY OF RECIFE: AN ANALYSIS BASED ON ITS \\ RELATIONSHIP WITH EDUCATION AND THE CIVILIZATIONAL PROCESS
}

MEMORIA DEL JUDO EN LA CIUDAD DE RECIFE: UN ANÁLISIS A PARTIR DE
SU RELACIÓN CON LA EDUCACIÓN Y EL PROCESO CIVILIZATORIO

Denis Foster Gondim*, Esdras Henrique Rangel de Melo*, Leandro Carlos Mazzei* ${ }^{*}$, Henrique Gerson Kohl* ${ }^{*}$ Vilde Gomes Menezes*

\section{Palavras chave:} Artes marciais. Judô. Aspectos históricos.
Resumo: Objetiva-se analisar a história do judô recifense e suas dimensões educacionais e civilizatórias por meio da técnica de análise de conteúdo das falas de antigos senseis de judô em Recife. Constatou-se que o judô possibilita a aprendizagem, formação para a vida constituída por regras e a formação ética/moral diante da sociedade, através de fatores como disciplina e hierarquia. As entrevistas indicam os ganhos do judô como modalidade esportiva e reconhece-se que o judô esportivizado atual teve perdas. Concluise que, dentre as modalidades esportivas, o judô ainda se diferencia por conta de suas características e especificidades filosóficas preconizadas por Jigoro Kano e sua incidência sobre a educação.
Keywords:

Martial arts.

Judo.

Historical aspects.
Abstract: This article aims to analyze the history of judo in Recife and its educational and civilizational dimensions by conducting content analysis about the speeches of old judo 'senseis' in that city. Judo was found to enable learning and education for life under ethical/ moral rules and education of society through factors such as discipline and hierarchy. Interviews point to judo's gains as a sport and recognize that the current sport-oriented judo has suffered losses. Among sports, judo is still distinguished by its characteristics and philosophical peculiarities advocated by Jigoro Kano and its influence on education.

Palabras clave: Artes marciales. Judo.

Aspectos históricos.
Resumen: El objetivo es analizar la historia del Judo de Recife y sus dimensiones educativas y civilizatorias a través de la técnica de análisis de contenido de los discursos de antiguos senseis de Judo en Recife. Se constató que el Judo posibilita el aprendizaje, la formación para la vida constituida por reglas y la formación ética/moral frente a la sociedad, a través de factores como disciplina y jerarquía. Las entrevistas mostraron los méritos del Judo como modalidad deportiva y reconocieron que el Judo deportivo actual tuvo pérdidas. Se concluye que, entre las modalidades deportivas, el Judo todavía se destaca, debido a sus características y especificidades filosóficas, preconizadas por Jigoro Kano, y por su incidencia sobre la educación.
*Universidade Federal de Pernambuco. Recife, PE, Brasil. E-mail: foster.denis@ @otmail.com; esdrashrm222@gmail.com; profhenriquekohl@ hotmail.com; vildemenezes@hotmail.com

**Universidade Estadual de Campinas. Campinas, SP, Brasil. E-mail: leandro.mazzei@fca.unicamp.br

Recebido em: 18-12-2018 Aprovado em: 03-08-2019 Publicado em: 22-11-2019

DOI https://doi.org/10.22456/1982-8918.87957 (c) (1) \&) Licence 


\section{INTRODUÇÃOO}

Ao tratar de pesquisas que objetivam a identificação de marcos históricos, a linha que divide o imaginário do real é sempre tênue e complexa. Pautando-se nessa problemática, 0 conhecimento sobre esportes estrangeiros e sua introdução no Brasil perpassa por alterações constantes advindas de novas descobertas, o que proporciona um campo com diferentes informações e pontos de vista por vezes divergentes (DEL PRIORE; MELO, 2009).

Destarte, a introdução do judô no Brasil ocorreu por meio da imigração japonesa e de inúmeros personagens que se fixaram no país e passaram a viver do ensino do judô, seja em um primeiro momento para os próprios imigrantes do Japão, seja em um segundo momento para toda comunidade e sociedade em que estavam inseridos (NUNES, 2013). Curiosamente, nem sempre esses imigrantes tinham formação adequada para o ensino pedagógico do judô, mas detinham conhecimento prático para disseminarem essa atividade para os interessados nos locais em que viviam (MAZZEl; CRUZ, 2015).

Por isso, podem-se relacionar pesquisas relevantes sobre o histórico do judô no Brasil: Drigo (2007); Farias (2012); Figueiredo (2012); Marta (2004, 2009, 2010); Mazzei e Cruz (2015); Nunes (2013) e Nunes e Rubio (2012), que trazem novas e diferentes informações não só sobre a chegada do judô ao Brasil, mas também sobre desenvolvimento da modalidade no país. Os estudos supracitados, de certa forma, aproximam-se de aspectos educacionais e civilizatórios dessa prática no país, sobretudo os de cunho histórico; mas, ao mesmo tempo, despertam diferentes possibilidades para a realização de mais pesquisas e estudos que busquem informações sobre as histórias e marcos civilizatórios relacionados com o judô e demais regiões do Brasil. Assim, o objetivo deste artigo foi investigar a história do judô recifense visando compreender suas dimensões educacionais e civilizatórias.

\subsection{O JUDÔ E O PROCESSO CIVILIZATÓRIO}

Com o fim da Segunda Guerra Mundial e os desdobramentos ocorridos no Japão, o judô passou por diferentes transformações (NIEHAUS, 2006; SATO, 2013). Brian Goodger, John Goodger (1977) e Régner (2010) afirmam que o judô sofreu forte institucionalização cultural por meio de um processo de "reculturação" ressignificando a marcialidade dessa arte em esportivização. Contudo, esses autores indicam que Jigoro Kano já buscava civilizar sua prática, visto que o judô foi desenvolvido a partir de práticas e movimentos tradicionais do Ju-jutsu, m que nesse processo foram excluídas técnicas mortais e demasiadamente violentas.

Elias (1994, v. 2, p. 193) afirma que um processo civilizatório é caracterizado por uma "mudança na conduta e sentimentos humanos rumo a uma direção muito específica". Nesse contexto, buscou-se compreender com o processo civilizatório que diferenças existem no que diz respeito à cultura ocidental e oriental na formação e evolução dos indivíduos em uma sociedade. Conceitualmente, o processo civilizatório pode ser definido como a "manipulação consciente de fontes culturais por atores sociais, derivando, igualmente, do aperfeiçoamento da consciência que os indivíduos possuem em relação ao meio que o cerca [sic]" (SOUZA, 2014, p. 104).

Destaca-se, então, que a origem do judô no Japão tinha como objetivo oferecer uma prática holística educacional contextualizada ao momento histórico daquele país no fim do século XIX, e também se buscava uma prática de desenvolvimento humano, ético e social (WATSON, 2011). Atualmente, o judô pode ainda ser considerado como um catalisador 
que possibilita aos interessados melhor convívio social norteado por normas civilizadoras e com bases filosóficas consistentes preconizadas pelo professor Jigoro Kano ainda em 1882. Portanto, a relevância educacional evidenciando que a história do judô do Recife ocorreu de forma processual, à luz da teoria eliasiana do processo civilizatório.

\section{METODOLOGIA}

Trata-se de um estudo de abordagem qualitativa, com propósitos exploratórios, preocupando-se, assim, com os aspectos da realidade, centrando-se na compreensão e explicação em profundidade da dinâmica das relações sociais. Minayo (2001, p. 22) afirma que a pesquisa qualitativa "trabalha com o universo de significados, motivos, aspirações, crenças, valores e atitudes, o que corresponde a um espaço mais profundo das relações".

Quanto aos procedimentos de análise e aos dados relacionados com a História Oral, Meihy e Holanda (2014) asseveram que existem três tipos: História Oral de vida, História Oral temática e Tradição oral. No caso da História Oral temática, abordagem que será usada neste trabalho, os autores a conceituam como um processo que delimita um tema e organiza a entrevista direcionada ao problema e objetos da pesquisa, neste caso, as fontes orais que circunvalam em torno da relação do judô e da educação a partir do conhecimento vivido pelos antigos mestres que ensinaram judô em Recife.

\subsection{FONTES DE INFORMAÇÃO}

Esta pesquisa deu relevo aos antigos mestres de judô mediante o processo de valorização e ressignificação desses professores, protagonistas de um importante marco histórico do judô recifense.

Os mestres participantes da pesquisa foram identificados por meio da análise documental realizada com 0 objetivo de delinear aquelas pessoas que foram mencionadas com maior frequência e significativamente presentes em reportagens e recortes históricos de jornais e revistas de determinado momento da história (1952-1972). A escolha desse período relaciona-se com os escassos achados históricos que mostram que, por volta dos anos 1950, alguns japoneses envolvidos com judô passaram pelo Recife na intenção de divulgação da arte marcial.

Ainda sobre o período escolhido para a investigação da pesquisa, existe a necessidade de um levantamento de fontes documentais relacionadas com o histórico do judô pernambucano, pois outras pesquisas (CAVALCANTE, 2014; NAGAI, S. H.; NAGAI, S. E., 1998) identificaram que o que se tem mais bem documentado, do ponto de vista historiográfico, está mais atrelado à fase posterior à fundação da Federação Pernambucana de judô em 1972. Tal informação fortaleceu a necessidade de realização desta pesquisa.

O critério de inclusão para a seleção dos entrevistados foi: ter sua história, total ou predominantemente ligada à modalidade judô no período histórico estabelecido. Também se decidiu que seriam excluídos da seleção mestres falecidos e a possibilidade de entrevistar terceiros (familiares e/ou amigos) destes, considerando a hipótese da ausência da riqueza de detalhes dos dados por esses terceiros. Por fim, os participantes assinaram o termo de consentimento e foram conduzidos a um local reservado para a realização da entrevista.

Dessa forma, os entrevistados foram os seguintes indivíduos (Tabela 1): 
Tabela 1 - Indivíduos participantes da pesquisa

\begin{tabular}{ccccc}
\hline Nome & $\begin{array}{c}\text { Data de } \\
\text { nascimento }\end{array}$ & Ano e local de início no judô & Mestre & $\begin{array}{c}\text { Chegada ao } \\
\text { Recife }\end{array}$ \\
\hline Diógenes C. Morais & $9 / 3 / 1930$ & 1950, Recife & Takeo Yano & 1942 \\
Byung Kuk Lee & $25 / 2 / 1936$ & 1950, Coréia do Sul & Kim Sang-Tae & 1967 \\
Hayashi Kawamura & $26 / 8 / 1936$ & $1945-1946$, Japão & Izuda & 1967 \\
Tadao Nagai & $6 / 7 / 1935$ & 1946, São Paulo & Ryuzo Ogawa & 1970 \\
Marco Aurélio & 1956 & 1973, Recife & José Alves & N/A \\
\hline
\end{tabular}

Fonte: Dados da pesquisa.

\subsection{ANÁLISE DOS DADOS}

Em face dos relatos obtidos pelas entrevistas, empregaram-se as técnicas desenvolvidas por Alberti (2005), Montenegro (2013) e Thompson (1992), para filtrar as informações e selecionar novas fontes de pesquisa advindas dos relatos dos entrevistados. Por último, os dados coletados pelas entrevistas submeteram-se aos procedimentos de análise de conteúdo.

A organização da análise de conteúdo dividiu-se em três fases: a) pré-análise (organização e leitura dos dados obtidos nas entrevistas); b) exploração do material (definição de categorias); c) tratamento dos resultados, a inferência e a interpretação (BARDIN, 2011; MINAYO, 2007).

No fim desse processo, submeteram-se os dados à análise pelo software NVivo; ${ }^{\circledR}$ a partir de então, codificaram-se os dados por meio de categorias de análise, para que fossem extraídas inferências pertinentes ao estudo (FRANCO, 2012). As categorias sistematizadas para análise foram: a) gênese do judô recifense; b) educação pelo judô; c) cultura judoística; d) sociedade e violência (Quadro 1).

Quadro 1 - Sistematização das categorias para análise de conteúdo do estudo

\begin{tabular}{|l|r|}
\hline a) Gênese do judô recifense & $\begin{array}{r}\text { Entrada no judô; origem e desenvolvimento do judô do Recife; } \\
\text { referências dos senseis }\end{array}$ \\
\hline b) Educação pelo judô & $\begin{array}{r}\text { Lições educativas do judô; princípios filosóficos e sua aplicabilidade prática; } \\
\text { complementação à formação educacional }\end{array}$ \\
\hline c) Cultura judoística & Disciplina e hierarquia; esportivização do judô \\
\hline d) Sociedade e violência & Aspectos civilizatórios do judô \\
\hline
\end{tabular}

Fonte: Dados da pesquisa.

\section{RESULTADOS E DISCUSSÃO}

Considerando o objetivo de investigar a história do judô recifense e suas dimensões educacionais e civilizatórias, faz-se pertinente dar relevo aos relatos dos envolvidos diretamente com a gênese do judô conforme exposto a seguir.

\subsection{GÊNESE DO JUDÔ NO RECIFE}

Primeiramente, destaca-se que Laydner e Takao (2013) sugerem que o judô tenha sido introduzido no estado em 1915, com a vinda de um grupo de lutadores à cidade do Recife. 
Dentre eles, estava Mitsuyo Maeda, pois o grupo transitava no Brasil realizando demonstrações e desafios marciais.

Para confirmar ou enriquecer a informação sobre a chegada do judô a Recife, perguntouse aos indivíduos: a) como procedeu sua entrada na prática do judô; b) qual a origem e o como se desenvolveu o judô na cidade do Recife; c) quais foram suas principais referências judoísticas.

As falas dos entrevistados foram sintetizadas pela técnica da análise de conteúdo por predominância de frequência das palavras e tratadas pelo software $\mathrm{NVivo}^{\circledR}$, obtendo-se a representação por "nuvem de palavras" (Figura 1).

Figura 1 - Categoria Gênese do judô no Recife, PE

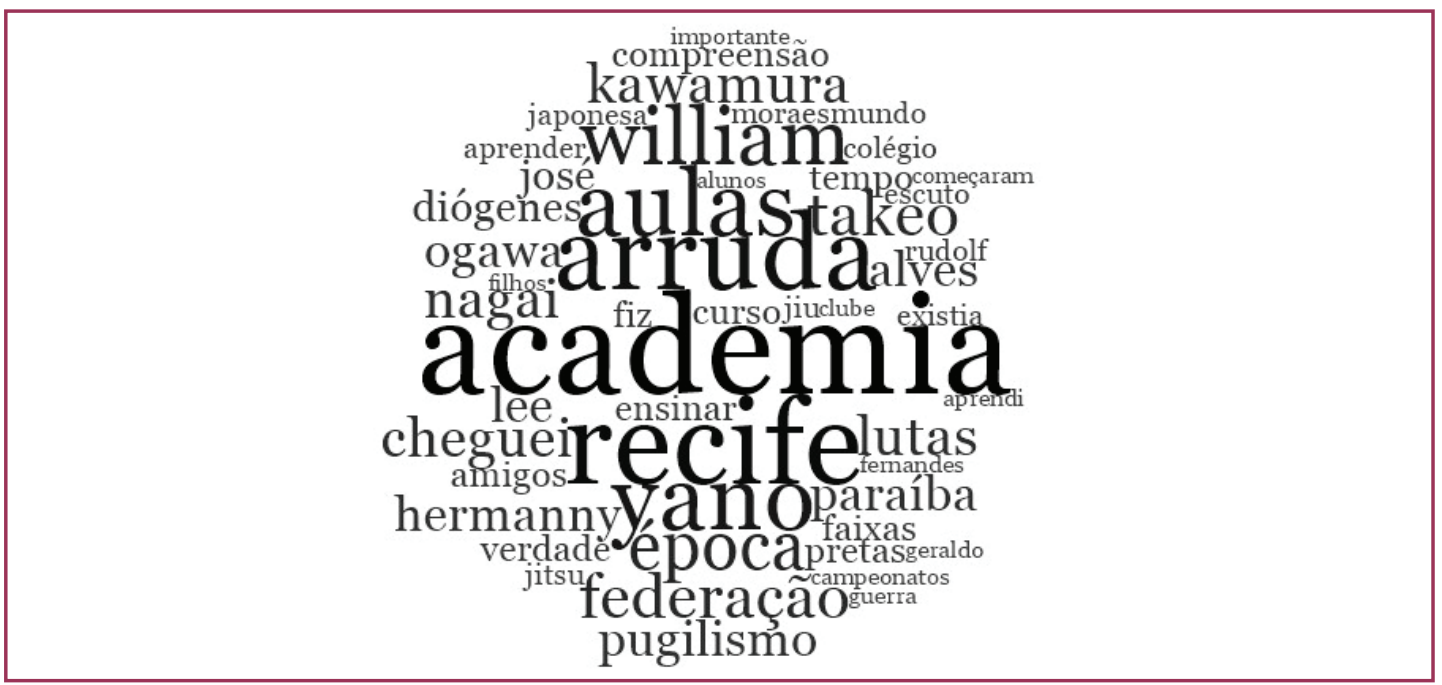

Fonte: Dados da pesquisa

Em face da interseção das falas, identificaram-se referências importantes do judô no cenário nacional, estadual e regional conforme foram mencionadas com maior contagem de frequência. Em associação à pesquisa documental, remontou-se graficamente a genealogia dos entrevistados, sintetizando sua influência e principais referências (Figura 2).

Figura 2 - Genealogia do judô em Recife segundo os senseis entrevistados

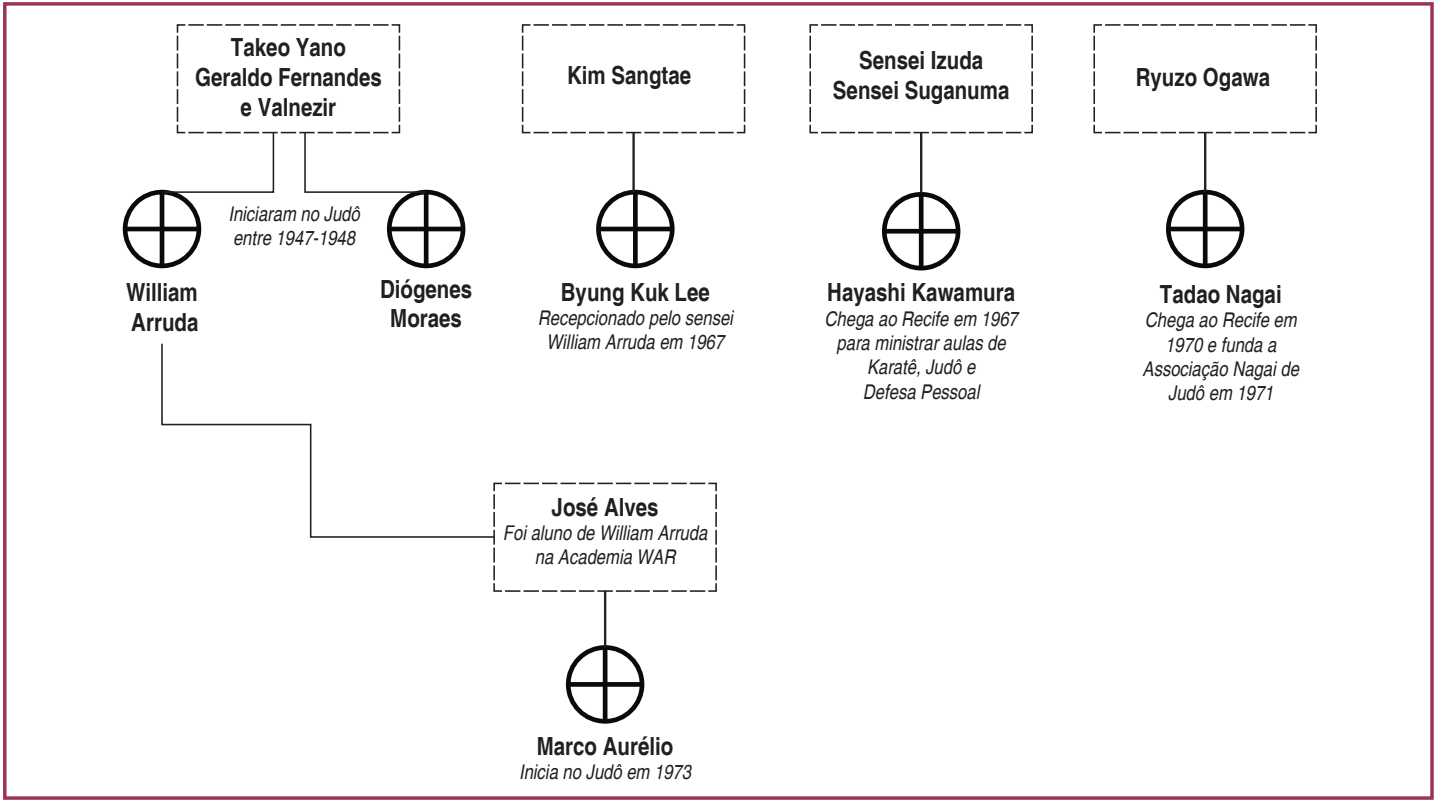

Fonte: Dados da pesquisa. 
Dessa forma, identificou-se que a introdução do judô provavelmente ocorrera a partir de 1947, e não em 1915, data em que supostamente houve uma exibição do Conde Koma na cidade.

\subsection{EDUCAÇÃO PELO JUDÔ}

Nesta categoria de análise, objetivou-se compreender a relação entre educação e judô na perspectiva dos entrevistados considerando as seguintes subcategorias: I) Lições educativas do judô; II) Princípios filosóficos e sua aplicabilidade; III) Complementação à formação educacional.

Na subcategoria I, inferiu-se, pela fala dos entrevistados, que o judô é uma ferramenta educacional que possibilita a formação para a vida constituída por regras, possibilitando 0 enfrentamento de obstáculos e a formação ética diante da sociedade, corroborando as assertivas de Benesch (2011) e Narroway (2008), de que o judô tinha o objetivo de regular a moral da vida social.

Em relação à subcategoria II, foi possível concluir que princípios filosóficos como melhor uso da energia, prosperidade e benefícios mútuos são condutores para uma postura íntegra e humana perante a sociedade (Figura 3).

Figura 3 - Categoria Educação pelo judô, subcategorias I e II

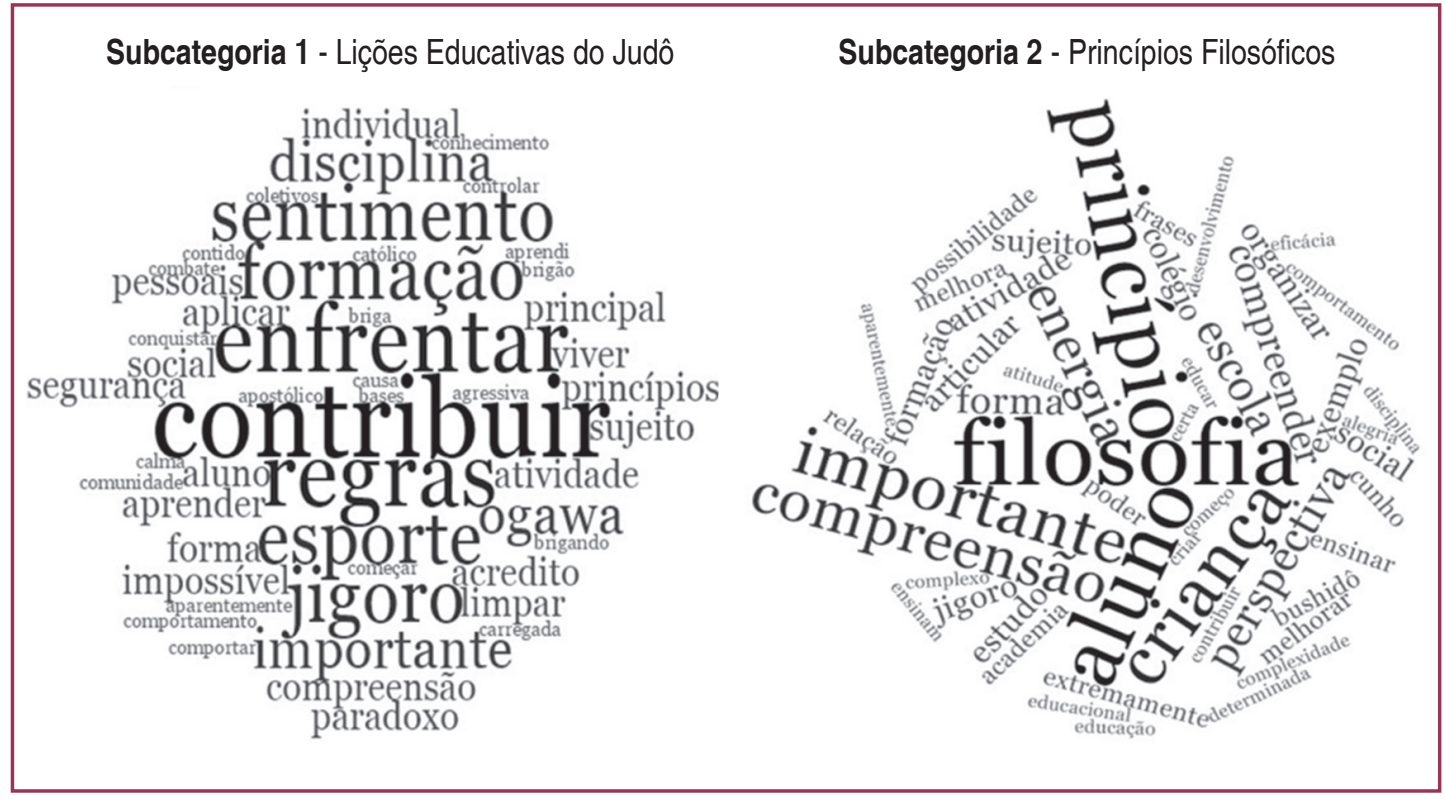

Fonte: Dados da pesquisa.

Desse modo, faz-se alusão a Carr (1993), Craig (1995) e Espartero (2016), que ponderam sobre o Judô Kodokan ter sido pensado por Jigoro Kano como um método sistemático de ensino que buscava o desenvolvimento da sociedade, assim pretendendo vir a ser um instrumento de formação integral individual e social.

Na subcategoria III (Figura 4), buscou-se compreender como se configura o judô como ferramenta de complementação à formação educacional. Sobre isso, verificou-se que os senseis compreendem o judô como ferramenta para complementação educacional dos 
praticantes (educação não formal ou não institucionalizada) quando associada à escola e à educação familiar.

Figura 4 - Categoria Educação pelo judô - subcategoria III complementação à formação educacional

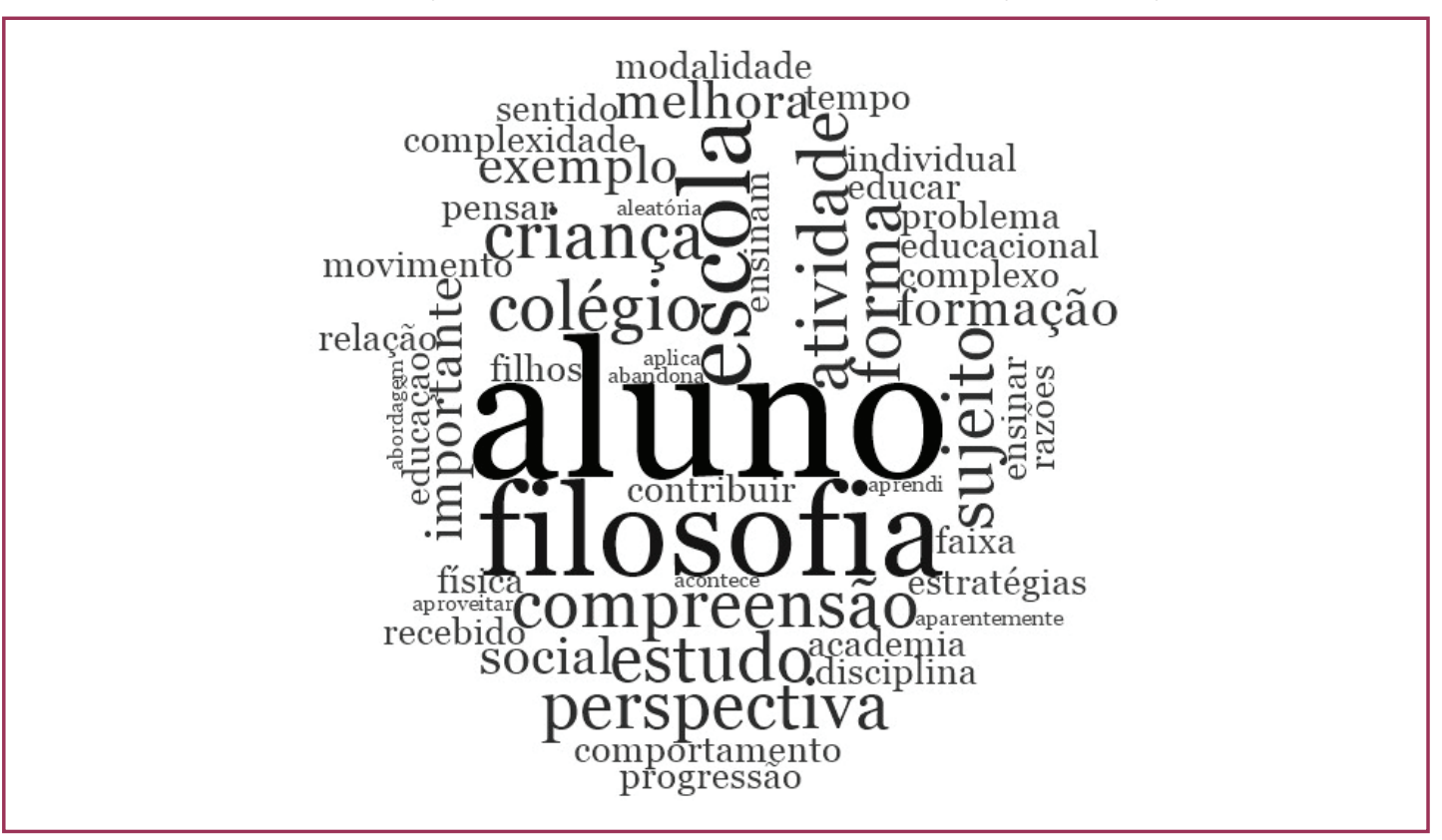

Fonte: Dados da pesquisa

Não é possível dissociar o judô da Educação, visto que seu criador lutou, desde a sua gênese, para que o sistema tivesse abrangência educativa. Deduz-se que um sensei humanista, com formação fundamentada por pilares filosóficos judoísticos, otimizará esta abrangência educativa, dado o estreito vínculo que o método de ensino de judô mantém com a educação (STEVENS, 2013), visto que Jigoro Kano, ao criar o judô, pretendia que fosse um instrumento de formação integral em nível individual e social (ESPARTERO, 2016), ou seja, "uma filosofia de vida na perspectiva de uma prática cidadã responsável e humanizada" (MENDES; MULERO, 2015).

\subsection{CULTURA JUDOÍSTICA}

Para esta categoria, buscou-se compreender as distinções contidas nas seguintes subcategorias provenientes da análise de conteúdo: I) Disciplina e Hierarquia; II) Esportivização do judô; III) Tradicionalismo no judô.

Na subcategoria disciplina e hierarquia, inferiu-se que, em razão da gênese do judô estar ligada aos conflitos e às batalhas oriundas do contexto cultural japonês pertinente à cultura samurai, seus aspectos marciais, guerras, batalhas, os fatores como disciplina e hierarquia (Figura 5) naturalmente fazem parte do contexto daqueles que praticam uma arte marcial "advinda de uma cultura que valoriza o autocontrole e a disciplina" (GONÇALVES; SILVEIRA, 2012, p. 134).

O que conduz ao entendimento de que o judô é um esporte de luta ideal que favorecerá a educação das crianças com o apoio familiar e a educação formal proporcionada pela escola em função do caráter disciplinador que as práticas judoísticas carregam (GONÇALVES; SILVEIRA, 2012). 
Figura 5 - Categoria Cultura Judoística

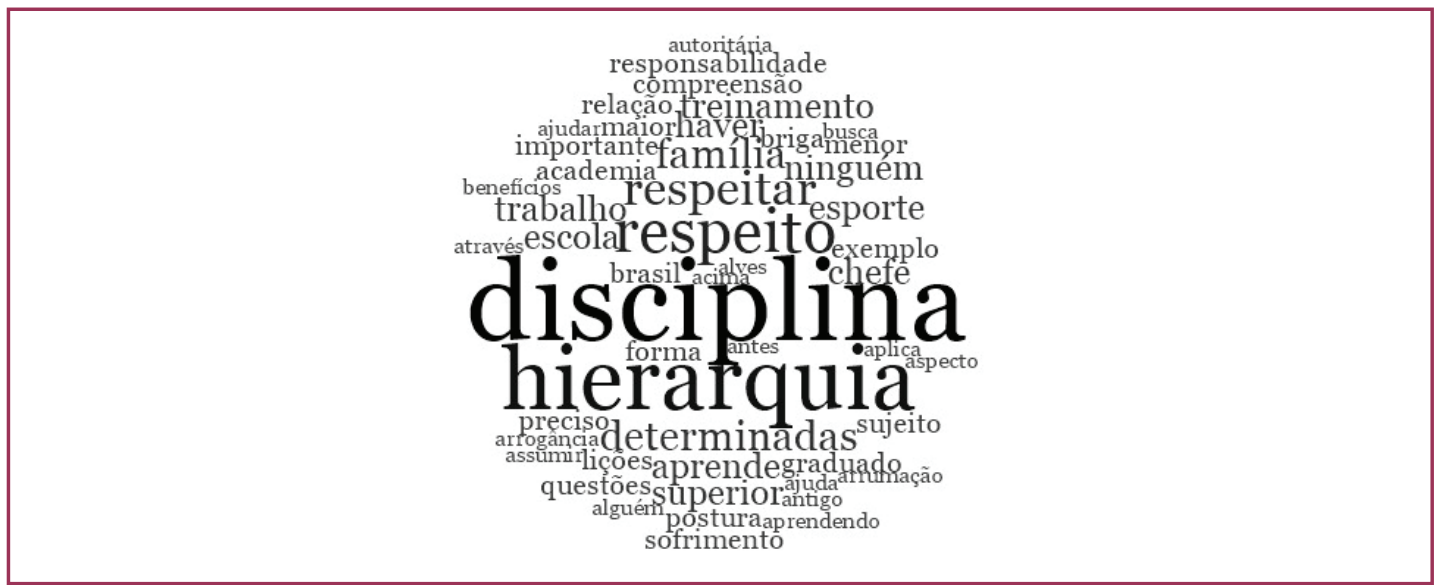

Fonte: Dados da pesquisa.

Esses aspectos culturais possibilitam ajustes educacionais e comportamentais aos seus praticantes (positivos e/ou negativos), já que o corpo na perspectiva educacional de Kano foi concebido como uma espécie de veículo (CADOT, 2007), dotado de uma interdependência entre aprimoramento individual - desenvolvimento do bem-estar - progresso social (SHIMIZU, 2008).

Para que possamos ampliar os horizontes quanto à compreensão do judô, faz-se necessário analisar o processo de esportivização sofrido por ele ao longo do tempo. Para tal, obtivemos os seguintes termos mais frequentes analisados via software: "ESPORTE", "OLIMPÍADAS", "EDUCAÇÃO", "ESPORTIVIZAÇÃO", "PROBLEMA", "MUNDO" e "MODALIDADE" (Figura 6).

Figura 6 - Categoria Cultura Judoística, subcategoria Esportivização do judô

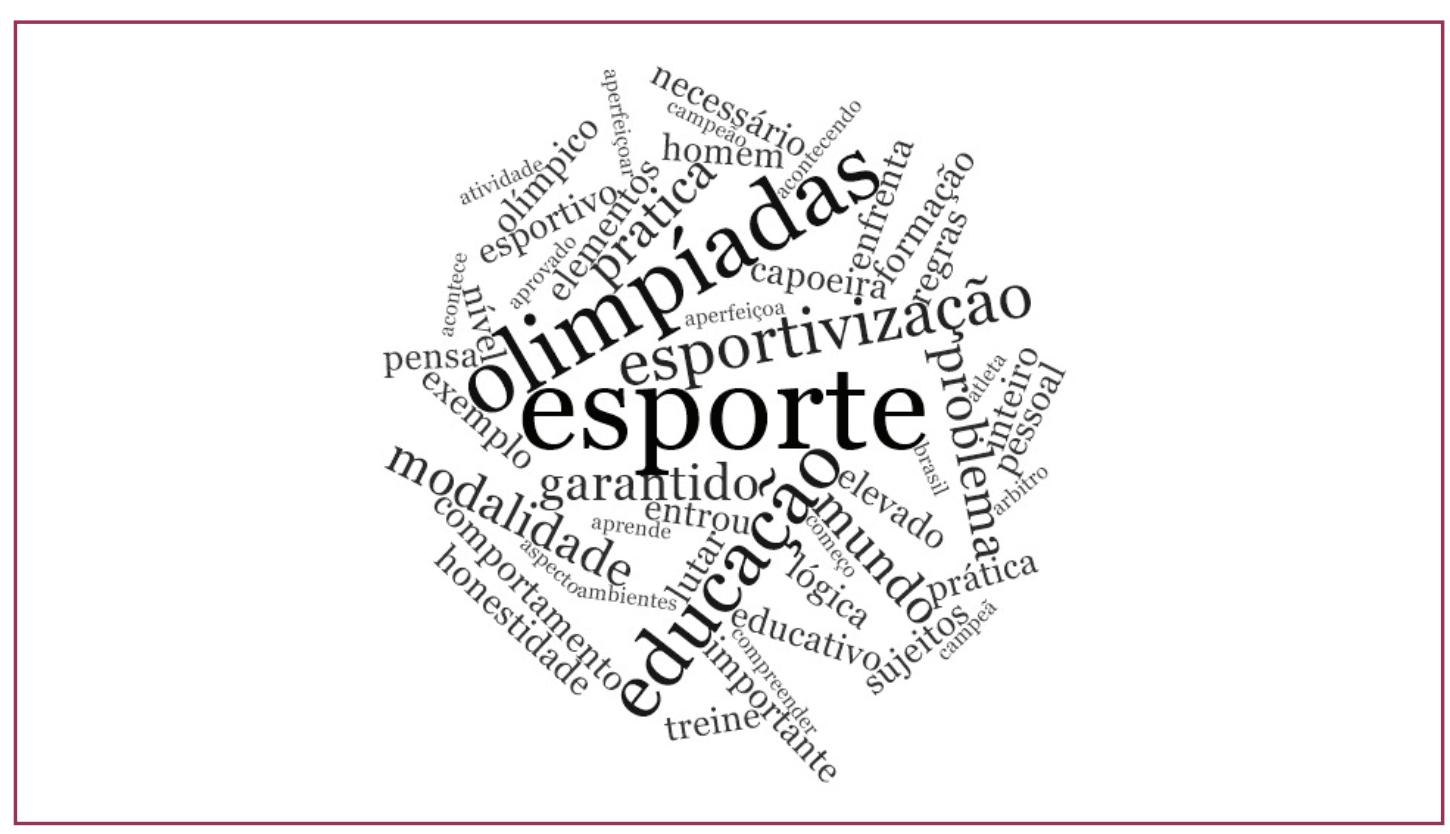

Fonte: Dados da pesquisa.

Assim, identificou-se que os entrevistados percebem o processo de esportivização do judô. Contudo, dentre os senseis entrevistados, a maioria (quatro dos cinco) valorizou os ganhos do judô como modalidade esportiva, e três entre cinco entrevistados reconheceram que o judô 
esportivizado atual teve perdas, já que a palavra "problema" representa essa preocupação por parte dos senseis da pesquisa.

Na há dúvida quanto à aproximação entre Jigoro Kano e o Ocidente, sobretudo para compreender mais sobre o modelo educacional, denotando uma pretensa expansão e massificação do judô em outros continentes por intermédio de seus principais alunos. Todavia, com a forte institucionalização da modalidade, criou-se uma rigidez que acabou por enfraquecer o lado "marcial" de cunho filosófico do judô por meio da massiva espetacularização da modalidade. É o que aponta Felipe Marta (2000):

O fato de ser disseminado no Ocidente parece ter contribuído para o processo de transição: 'de arte marcial para esporte'. Pois, uma vez que entrou em contato com a razão e o modo de vida do Ocidente, o Taekwondo foi cercado de uma série de influências (lazer, violência nas cidades, ritmo de vida, treinamento esportivo, marketing, mídia, lucro, etc.) das quais não pôde se manter livre (MARTA, 2000, p. 687).

Embora o autor aborde outra arte marcial, o Taekwondo, Marta (2000) faz uma descrição acurada sobre o processo de esportivização de uma arte marcial, em que os professores "[...] esbarram nos princípios (características básicas) do esporte moderno: competição, rendimento físico-técnico, record, racionalização e cientifização do treinamento" (BRACHT, 1997, p. 10).

Por fim, emular de forma radical o Oriente no Ocidente por intermédio das artes marciais pode não ser uma estratégia interessante, o que pode dar indícios do fortalecimento do processo de esportivização do judô, já que nos dojôs possivelmente há uma "exacerbação de um 'espírito' competitivo" (UENO; SOUSA, 2014, p. 1).

O próprio Kano visava civilizar sua prática, visto que, da transformação do antigo Ju-Jutsu dos samurais, ele codificou a sua nova prática excluindo técnicas mortais ou demasiadamente violentas, facilitando sua popularização, já que agora o novo sistema podia ser praticado da criança ao idoso, pois não havia chance de lesões.

De acordo com Brian Goodger e John Goodger (1977) e Régner (2010), o judô é compreendido na Europa como uma arte marcial que, por meio de um processo de "reculturação", sofreu forte institucionalização cultural que ressignificou a marcialidade do judô (já mencionado), destacando-se aqui o supracitado processo civilizatório correlato às práticas judoísticas.

Régner (2010, p. 93) pondera que "seria mais apropriado colocar o judô como uma prática puramente heterodoxa para o Japão da época, mas perfeitamente ortodoxa quanto ao modo de prática ocidental". Isso denota que a contextualização cultural é fator determinante para a assimilação do judô pela sociedade em que ele se insere ou se desenvolve. Assim, o que se pretende enfatizar é a necessidade da consciência por parte da sociedade que se espera boa convivência e respeito recíproco mediante normas condizentes de civilidade.

Compreendemos que lutar é interagir sabendo respeitar o próximo, independentemente do resultado, e privilegiando sempre a integridade física do oponente acima de qualquer coisa. Entretanto, é de conhecimento que as artes marciais se originam da cultura oriental, bastante distinta da ocidental. Sobre as artes marciais orientais, Marta (2010, p. 29) ressalta que, ao longo do século XX, "delas foram gradualmente retirados ou sublimados os gestos considerados violentos em demasia", o que o autor batiza como "controle da violência potencial".

Entretanto, Marta ressalta que essas práticas sofreram ajustes em tempos diferentes e ainda algumas delas se utilizam atualmente de crítica a esse controle da violência buscando 
construir uma ferramenta de marketing para que se justifique sua difusão. A exemplo disso, cita o jiu-jítsu brasileiro voltado para a concepção de retorno da violência mediante práticas como o vale-tudo, razão pela qual entendemos que, de certa forma, tal postura caracteriza-se como um retrocesso civilizador de "desesportivização".

Ainda de acordo esse autor:

[...] existem artes marciais criadas no Ocidente que foram lentamente convertidas em jogos que, em alguns casos, posteriormente, foram convertidos em esportes como resultado de um processo de amenização ou suspensão daqueles elementos considerados violentos ou bárbaros para as novas sensibilidades 'civilizadas' que foram se desenvolvendo na Europa (MARTA, 2010, p. 47).

No entanto, os esportes de combate e as artes marciais têm a particularidade do confronto direto e do "tocar no outro". Pensando em um dos pilares da teoria, referente ao controle das emoções, as práticas desse cunho têm maior necessidade de não extrapolar suas emoções e não incorrer em desvios para a violência. Por outro lado, a regulamentação das lutas por meio de sua esportivização projeta-as para culturas civilizadas e bem-aceitas, por exemplo, o entendimento do fair play (jogo limpo) ou respeito recíproco para além das regras em si, que é tão bem-aceito na concepção de esporte moderno.

No que corresponde ao judô, Marta (2010, p. 54) afirma ter sido a "primeira arte marcial oriental a expressar um sentido pedagógico que, ao mesmo tempo em que buscava a difusão e manutenção de valores morais tradicionais japoneses, buscava também fundir esses valores a aspectos pedagógicos ocidentais". Entendemos que essa base filosófica por parte do judô permite que seja bem guiado de acordo com os princípios que o constituem, tornando sua prática mais segura.

Um dos pilares filosóficos do judô é o Jita Kyoei, que, em sua essência, significa prosperidade e benefícios mútuos, ou seja, o indivíduo só cresce e se desenvolve a partir do crescimento coletivo. Assim, é possível percebermos aproximações conceituais entre 0 pensamento de Kano e o de Elias.

De acordo com Tania Quintaneiro (2010), Elias entende a sociedade por uma perspectiva sociológica figuracional, pela qual, segundo a autora, ele assinala que:

\footnotetext{
[...] em nossa era, a tendência é de que 'mais e mais grupos e, com eles, mais e mais indivíduos' dependam 'uns dos outros para sua segurança e a satisfação de suas necessidades [...]' e que esta interdependência social acaba favorecendo com que as pessoas apenas consigam 'sustentar sua vida e sua existência social em conjunto com muitas outras' (QUINTANEIRO, 2010, p. 55).
}

Destarte, fica claro que Kano, assim como Elias, compreendia e preconizava que a convivência social era ditada pelo respeito ao próximo, guiado por normas de civilidade e controle de emoções.

Quanto ao processo civilizatório do judô em Recife, analisando a Figura 7, constatamos uma prevalência das seguintes palavras: "PROFESSOR", "DEFENDER", "REALIDADE", "MEDIADOR", "COMPREENSÃO", "RELAÇÃO", "ALUNO", "ENFRENTAR", "VIOLÊNCIA", "FAMÍLIA" e "ENSINANDO". Ao analisarmos os dados, é possível deduzirmos que os entrevistados compreendem que as artes marciais têm capacidade para formar o cidadão em busca de uma sociedade mais equilibrada emocionalmente. 
Figura 7 - Aspectos civilizatórios do judô segundo os entrevistados

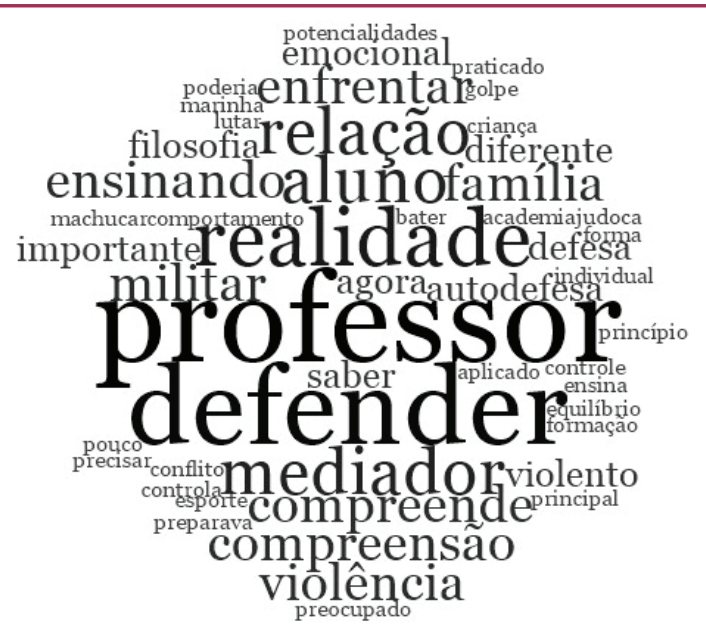

Fonte: Dados da pesquisa.

De acordo com Almeida et al. (2009, p. 166), "um ponto importante na obra de Elias é a compreensão da necessidade de domar os instintos violentos", nessa lógica, o papel do judô diante dessa possibilidade.

O caminho de uma arte marcial até transformar-se em uma modalidade esportiva de combate leva-nos, por meio de seus sistemas regrados e burocratizados, a uma representação clara e direta do processo civilizatório direcionado para um controle da violência (ALMEIDA et al., 2009). Em outras palavras, pode-se dizer que, ao transformá-la em esportes, as próprias inclusões e o desenvolvimento de regras contribuem para que haja uma espécie de controle social, no sentido de reduzir a violência, seja na intenção de proteção, seja de maior respeito à integridade física do oponente, seja por um julgamento social que cerceia a possibilidade de ter-se a violência exaltada mediante o esporte.

Essa mesma teia relacional, por onde ocorrem episódios nos mais diversos âmbitos sociais, é prevista pela teoria do processo civilizatório em que a sociedade é moldada por costumes e hábitos que são dinâmicos e mediados por uma inter-relação na cadeia social em questão. Percebemos aproximações conceituais entre os fundamentos teóricos de Kano (2008) e os de Elias (1994), pois é perceptível que o criador do judô compreendia a importância emocional dos indivíduos perante suas inter-relações sociais, em que "a educação moral deve ser implementada com base no aspecto das emoções" (KANO, 2008, p. 59), e com isso, ele pretendia comunicar que um indivíduo treinado emocionalmente (capacidade de exercer o autocontrole) torna-se mais hábil em lidar com relações sociais e discernir melhor sobre suas ações e tomadas de decisão.

Em se tratando de artes marciais e/ou esportes de combate, mais especificadamente do judô, compreendemos que a sociedade contemporânea passa por diversas tensões emocionais (guerras, crises econômicas, políticas, etc.) que levam ao aumento da violência de forma geral.

Segundo Pimenta (2009, p. 5) "o processo civilizador está ligado ao ganho progressivo de autocontrole por parte dos indivíduos, autocontrole necessário para a convivência social e para o progresso industrial e comercial". Também entendemos que práticas de lutas, artes marciais e/ou esportes de combate que tenham algum tipo de propósito filosófico por trás de sua idealização, como é o caso do judô, facilitam a condução de seus praticantes, há um estado de maior autoconhecimento, sabedoria e maior controle de suas emoções. 


\subsection{SOCIEDADE E VIOLÊNCIA}

Nesta última categoria de análise, os senseis foram "provocados" a se posicionar sobre como a prática de uma arte marcial, luta ou esporte de combate pode relacionar-se com aspectos da violência social. Assim, busca-se posicionar a prática do judô em relação ao controle das emoções e da excitação preconizado pela análise da teoria eliasiana. Para tal discussão, nos dados representados na Figura 8, constatou-se a prevalência das seguintes palavras: "PROFESSOR", "DEFENDER", "REALIDADE", "MEDIADOR", "COMPREENSÃO", "RELAÇÃO", "ALUNO", "ENFRENTAR", "VIOLÊNCIA", "FAMÍLIA" e "ENSINANDO".

Ao ponderar sobre as falas de cada sensei, é possível inferir que eles compreendem que as artes marciais são dotadas da capacidade para formar o cidadão voltado para uma sociedade mais equilibrada emocionalmente. Nesse caso, assumindo claramente que o processo de esportivização do judô é real, uma vez que "algumas manifestações de lutas/artes-vias marciais passaram pelo processo de esportivização na modernidade" (UENO; SOUSA, 2014, p. 3), o esporte passa a desempenhar o papel de amainar as tensões sociais (ELIAS; DUNNING, 1992).

Outrora importantes enquanto possibilidade de manutenção da sobrevivência de guerreiros, atualmente as artes marciais foram reestruturadas para novas formas de utilização, tais como disputar uma competição e confrontar um adversário por meio de seus sistemas de regras e normas voltadas para um processo civilizatório de controle da violência (ALMEIDA et al., 2009). Afinal, o que se pretende é civilizar a arte marcial dantes "rude", "violenta" e "agressiva", já que no judô havia um alinhamento com a educação moral, e esta "deve ser implementada com base no aspecto das emoções" (KANO, 2008, p. 59), e com isso o criador do judô pretendia anunciar que um indivíduo treinado emocionalmente tornar-se-á mais hábil no trato com relações sociais.

\section{CONSIDERAÇÕES FINAIS}

À frente de seu tempo, Jigoro Kano buscou grandes aproximações com a cultura ocidental, sobretudo com as concepções europeias de educação, para assim desenvolver um sistema de luta voltado à formação física e moral dos indivíduos que teria viés marcial, mas, em consequência de um processo civilizatório, foi transformando-se em modalidade esportiva de combate, conforme as falas dos senseis apontaram.

Quanto ao ambiente da prática educacional denominado dojô, constatou-se que este pode ser considerado como "sala de aula" por onde se facilita o "caminho" literal da educação. Logicamente, a qualidade do sensei à frente desse processo será de extrema importância, haja vista que caberá a esse líder "educar" seus alunos, embasado pelos preceitos educacionais do judô preconizados por Jigoro Kano e em convergência com a cultura social local da configuração judoística em questão. A não formalidade desse "espaço" (no sentido da não institucionalização) facilitará para que sejam favorecidos momentos de aprendizagem que extrapolem seus muros e favoreçam uma educação para a vida daqueles que ali estão a aprender para além do judô em si.

Quanto ao processo civilizatório vivenciado pelo judô ao longo de seu trajeto histórico, pudemos constatar duas inferências: uma positiva e outra negativa. A positiva relacionada com o fato de que o próprio Jigoro Kano, em seu plano de difusão do judô pelo mundo, pretendia, mediante as bases educacionais, favorecer a exclusão de gestos violentos do antigo Ju-Jutsu 
para o desenvolvimento de uma prática de luta mais pedagógica.

Contudo, ao transformar o judô em esporte olímpico e, consequentemente, render-se ao mercado esportivo, os preceitos educacionais e filosóficos acabaram sendo preteridos em razão da busca por medalhas. Dessa forma, entendemos que a teoria civilizatória aplicada às práticas marciais possibilita a ocorrência de resultados positivos e negativos, dependendo, assim, do ângulo em que se analisa e o que se quer de cada prática.

Por fim, ressaltamos algumas limitações do estudo. Considerando o desenho do estudo, faz-se necessário ampliar as fontes históricas, sobretudo as relativas à História Oral. Assim, seria possível incluir outras fontes e informações sobre a gênese do judô no Recife e outras regiões do Brasil, já que é possível que, em determinado momento histórico no país, os indivíduos tenham compartilhado experiências e conhecimentos, o que poderia provocar semelhanças ou não dos resultados apresentados neste artigo.

\section{REFERÊNCIAS}

ALBERTI, Verena. Manual de história oral. 3. ed. Rio de Janeiro: FGV, 2005.

ALMEIDA, Marco Antonio Bettine et al. O processo civilizatório da marcialidade e a figura feminina. Movimento \& Percepção, v. 10, n. 14, p. 164-179, 2009.

BARDIN, Lawrence. Análise de conteúdo. São Paulo: Edições 70, 2011.

BENESCH, Oleg. Bushido: the creation of a martial ethic in late Meiji Japan. 2011. Thesis (Doctor of Philosophy - Ph.D.) - University of British Columbia, Vancouver, 2011.

BRACHT, Valter. Sociologia crítica do esporte: uma introdução. Vitória: UFES, 1997.

CADOT, Yves. Kanô Jigorô et le corps véhicule. In: BROTONS, Arnaud; GALAN, Christian J. (dir.). Japon pluriel. COLLOQUE DE LA SOCIÉTÉ FRANÇAISE DES ÉTUDES JAPONAISES, 7., 2007, Arles. Actes [...]. Arles: Philippe Picquier, 2007. p. 81-90.

CARR, Kevin Gray. Making way: war, philosophy and sport in Japanese judo. Journal of Sport History, v. 20, n. 2, p. 167-88, 1993.

CAVALCANTE, Márcio Eustáquio Lopes. Civilização e educação de artistas marciais: os saberes através da prática do judô, 1970-1980. 2014. 166 f. Tese (Doutorado em Educação) Universidade Federal de Pernambuco, Recife, 2014.

CRAIG, Darrell Max. Japan's ultimate martial art: jujitsu before 1882 the classical Japanese art of self-defense. Boston: Charles Tittle, 1995.

DEL PRIORE, Mary; MELO, Victor Andrade de. História do esporte no Brasil: do Império aos dias atuais. São Paulo: Editora da Unesp, 2009.

DRIGO, Alexandre Janotta. 0 judô: do modelo artesanal ao modelo científico: um estudo sobre as lutas, formação profissional e a construção do habitus. 2007. 250 f. Tese (Doutorado em Educação Física) - Universidade Estadual de Campinas, Campinas, 2007. 
ELIAS, Norbert. 0 processo civilizador. 2. ed. Rio de Janeiro: J. Zahar, 1994. 2 v.

ELIAS, Norbert; DUNNING, Eric. A busca da excitação. Lisboa: Difel, 1992.

ESPARTERO, Julian. The body seen by Kodokan Judo: an educational project of progress hampered by political reaction. Movimento, v. 22, n. 4, p. 1265-1276, 2016.

FARIAS, Cláudia Maria de. Sonhos, lutas e conquistas: projeção e emancipação social das mulheres brasileiras nos esportes, 1932-1979. 2012. 246 f. Dissertação (Doutorado em História) - Universidade Federal Fluminense, Niterói, 2012.

FIGUEIREDO, Aguinaldo Nascimento. Os samurais das selvas: a presença japonesa no Amazonas. Manaus: Edições Muiraquitã, 2012.

FRANCO, Maria Laura. Análise de conteúdo. 4. ed. Brasília, DF: Liber Livro, 2012. (Série Pesquisa, v. 6).

GONÇALVES, Arisson Vinícius Landgraf; SILVEIRA, Raquel da. Arte marcial e esporte: um estudo etnográfico sobre uma equipe de judô de Pelotas-RS. Movimento, v. 18, n. 2, p. 129147, abr.jjun. 2012.

GOODGER, Brian C; GOODGER, John M. Judo in the light of theory and sociological research. International Review of Sport Sociology, v. 12, n. 2, p. 5-34, jun. 1977. Disponível em: http:// journals.sagepub.com/doi/abs/10.1177/101269027701200201. Acesso em: 20 jan. 2017.

KANO, Jigoro. Energia mental e física: escritos do fundador do Judô. São Paulo: Pensamento, 2008.

LAYDNER, Luiz Otávio; TAKAO, Fabio Quio. Exclusivo: Maeda ensinava Jiu-jitsu no Rio 10 anos antes dos Gracies. 0 Globo, 2 set. 2013. Disponível em: http://forum.portaldovt.com.br/ forum/index.php?/topic/161975-maeda-ensinava-jiu-jitsu-no-rio-10-anos-antes-dos-gracies/. Acesso em: 19 set. 2019.

MARTA, Felipe Eduardo Ferreira. A história do taekwondo no estado de São Paulo. In: CONGRESSO BRASILEIRO DE HISTÓRIA DA EDUCAÇÃO FÍSICA, ESPORTE, LAZER E DANÇA, 7., 2000, Gramado. Anais [...]. Porto Alegre: Universidade Federal do Rio Grande do Sul, 2000. p. 684-689.

MARTA, Felipe Eduardo Ferreira. 0 caminho dos pés e das mãos: taekwondo arte marcial, esporte e a colônia Coreana em São Paulo, 1970 a 2000. 2004. 138 f. Dissertação (Mestrado em História) - Pontifícia Universidade Católica, São Paulo, 2004.

MARTA, Felipe Eduardo Ferreira. A memória das lutas ou o lugar do "DO": as artes marciais e a construção de um caminho oriental para a cultura corporal na cidade de São Paulo. 2009. 203 f. Tese (Doutorado em História) - Pontifícia Universidade Católica, São Paulo, 2009.

MARTA, Felipe Eduardo Ferreira. A memória das lutas: as artes marciais orientais e a sua presença na cultura corporal de São Paulo. São Paulo: Educ, 2010.

MAZZEI, Leandro Carlos; CRUZ, Ana Carolina Costa. Um longo caminho: memória institucional da gestão do judô no Brasil. In: ROCCO JÚNIOR, Ary José et al. (org.). Ensaios sobre gestão do esporte: reflexões e contribuições do GEPAE/EEFE-USP. [recurso eletrônico]. Sarapuí, SP: OJM, 2015. p. 105-128. Disponível em: https://www.researchgate.net/profile/Rogerio Voser/ publication/318205233 Relato das Praticas de Gestao em uma Organizacao Esportiva 
MEIHY, José Carlos Sebe Bom; HOLANDA, Fabíola. História oral: como fazer, como pensar. 2. ed. São Paulo: Contexto, 2014.

MENDES, Michael Reyne; MULERO, Andre Uitiro Munekata. O judô e a formação cidadã. Revista de Educação do Cogeime, v. 24, n. 47, p. 59-68, 2015.

MINAYO, Maria Cecília de Souza (org.). Pesquisa social: teoria, método e criatividade. Petrópolis: Vozes, 2001.

MINAYO, Maria Cecília de Souza. 0 desafio do conhecimento: pesquisa qualitativa em saúde. São Paulo: Hucitec, 2007.

MONTENEGRO, Antônio Torres. História oral e memória: a cultura popular revisitada. 6. ed. São Paulo: Contexto, 2013.

NAGAI, Silvana Harumi; NAGAI, Sérgio Eiji. 0 judô e vida do atleta e professor Tadao Nagai. 1998. 82 f. Monografia (Graduação em Educação Física) - Universidade Federal de Pernambuco, Recife, 1998.

NARROWAY, Lisa. Symbols of state ideology: the samurai in modern Japan. New Voices, v. 2, p. 63-79, 2008.

NIEHAUS, Andreas. If you want to cry, cry on the green mats of Kôdôkan: expressions of japanese cultural and national identity in the movement to include judo into the Olympic programme. International Journal of the History of Sport, v. 23, n. 7, p. 1173-1192, 2006.

NUNES, Alexandre Velly. Judô: Caminho das medalhas. São Paulo: Kazuá, 2013.

NUNES, Alexandre Velly; RUBIO, Kátia. As origens do judô brasileiro: a árvore genealógica dos medalhistas olímpicos. Revista Brasileira de Educação Física e Esporte, v. 26, n. 4, p. 667678, out./dez. 2012.

PIMENTA, Thiago. Racionalizando o machucar: processo civilizador e as artes marciais. In: SIMPÓSIO INTERNACIONAL PROCESSO CIVILIZADOR, 12., 2009, Recife. Anais [...]. Recife: [S. n.], 2009. Disponível em: http://www.uel.br/grupo-estudo/processoscivilizadores/portugues/ sitesanais/anais12/artigos/pdfs/comunicacoes/C Pimenta.pdf. Acesso em: 19 set. 2019.

QUINTANEIRO, Tania. Processo civilizador, sociedade e indivíduo na teoria sociológica de Norbert Elias. Belo Horizonte: Argvmentvm, 2010.

RÉGNIER, Patrice. Le judo en bretagne du point de vue de la théorie du processus de civilisation. Aspects Sociologiques, v. 17, n. 1, p. 86-98, 2010. Disponível em: http://www. aspects-sociologiques.soc.ulaval.ca/sites/aspects-sociologiques.soc.ulaval.ca/files/regnier2010 0.pdf. Acesso em: 19 set. 2019.

SATO, Shohei. The sportification of judo: global convergence and evolution. Journal of Global History, v. 8, n. 2, p. 299-317, 2013.

SHIMIZU, Satoshi. The body envisioned by Jigorō Kanō: based on his career as a jūdo master, IOC member and principal of Tokyo Higher Normal School. Ido-Movement for Culture: Journal of Martial Arts Anthropology, v. 8, n. 8, p. 29-37, 2008.

SOUZA, Ricardo Luiz de. Processo civilizador, poder e sociedade: introdução ao pensamento de Norbert Elias. Curitiba: CRV, 2014. 
STEVENS, John. The way of judo: a portrait of Jigoro Kano \& his students. Boston: Shambhala, 2013.

THOMPSON, Paul. A voz do passado: história oral. Rio de Janeiro: Paz e Terra, 1992.

UENO, Viviane Lopes Freitas; SOUSA, Marcel Farias de. Agressividade, violência e budō: temas da educação física em uma escola estadual em Goiânia. Pensar a Prática, v. 17, n. 4, out./dez. 2014.

WATSON, Brian N. Memórias de Jigoro Kano: o início da história do judô. São Paulo: Cultrix, 2011. 